\title{
On Recognising the Paradox of Sex
}

\author{
Foachim Dagg§
}

\begin{abstract}
George C. Williams and John Maynard Smith arrived at slightly different conclusions about the evolutionary maintenance of sexual reproduction, despite that both were staunch neo-Darwinians, simply because they approached the problem from different angles (life history vs. population genetics). This difference between their perspectives made them notice the so-called paradox of sexual reproduction for the first time. That is, Williams and Maynard Smith used their difference in perspective constructively, in order to raise a problem that had previously been overlooked by 'monocular' views. Evidence from before, during and after the recognition of the paradox supports this thesis of constructive difference. First, Maynard Smith had diagnosed the individual cost of sexual reproduction in full detail by 1958, but nobody raised an eyebrow for a decade. Second, both the correspondence between Williams and Maynard Smith and their publications show that they saw the same problem but against different backgrounds, because they viewed it from different perspectives. Third, further differences between Williams and Maynard Smith concerning the evolution of sex make no sense except in the light of the initial difference in their perspectives.
\end{abstract}

\begin{abstract}
Keywords
maintenance of sex $\bullet$ maintenance of recombination $\bullet$ group selection $\bullet$ life-history theory $\bullet$ population genetics $\bullet$ cost of sex $\bullet$ cost of meiosis $\bullet$ cost of males
\end{abstract}

\section{Introduction}

Discussions of the implications of sexual reproduction have appeared throughout the history of evolutionary biology, from Darwin to Weismann, Fisher, Muller, Maynard Smith, and Williams (see e.g., Churchill 1968, 2010; Mooney 1993, 1995; Lustig 2000; Winther 2001; Meirmans 2009; Meirmans and Strand 2010). The latest of these appearances highlighted an evolutionary paradox that had previously been overlooked. In many animal and plant species reproduction is obligately sexual and also half the offspring are male, yet the males contribute nothing but genes to reproduction. If asexual mutants of such a species were to produce as many asexual offspring on average as sexual females in that species produce daughters and sons, the growth rate of their population would be twice as large. Whereas half the offspring of sexual females are noncontributory males, all the offspring of such an asexual mutant would contribute to growth rate. Nevertheless, sexual reproduction prevails in most species and is not lost evolutionarily.

This paradox of sex became topical in the early 1970s. Why not earlier? Inquiring into the provenance of this problem raises several issues: What exactly was the problem? What happened in the period before it was recognised? Who recognised it for the first time, and why? The short answer to the last question is: George G. Williams and John Maynard Smith. They recognised it because they had different

$\S$ Hausener Weg 25, 65760 Eschborn, Germany

E-mail: jdagg@gmx.de

Received 24 April 2016; Accepted 1 May 2016 
perspectives on the benefit of sex, but used their difference as a starting point for inquiry rather than as a basis for dismissing each other. The following will address these questions in more detail.

Simply trying to isolate the paradox of sex is already perplexing, because even when related issues like sex determination, sex allocation, and sexual selection are set aside, two intricately-related problems remain: the evolutionary maintenance of sexuality (MS) and the evolutionary maintenance of recombination (MR). These can be separated conceptually only with respect to what question is being asked (i.e. which evolutionary costs pose a challenge to sexual reproduction) and which observations are treated as requiring explanation. However, the central effect of sexual recombination, undoing linkage disequilibria, affects both the MS and the MR. The issues are mechanistically linked and cannot be entirely separated.1]

\section{Before the paradox: a timeline}

The following historical sources illustrate the slow realisation that previously accepted explanations of the significance of sexual reproduction implied a benefit to populations or species rather than to individuals. Such a benefit had often been taken to require group selection. By the end of the 1950s, geneticists had fully realised that sexual recombination cannot benefit individuals directly (e.g., Mather 1943; Fisher 1958; Muller 1958; Maynard Smith 1958; Stebbins 1959 in Tax and Callender 1960). However, for another decade none perceived this situation as anomalous or paradoxical.

\section{Fisher in 1930 and Muller in 1932}

Fisher ([1930]1999: 121-123) defined the rate of evolutionary progress as the rate with which beneficial mutations become fixed in a population. A beneficial mutation must have increased to a considerable frequency in an asexual population before a second one has a good chance of occurring in an individual already carrying the first. Otherwise, the two beneficial mutations would necessarily compete. In sexual populations, however, beneficial mutations can arise in different individuals simultaneously, yet grow to fixation independently, because of recombination (see also Mooney 1995).

\footnotetext{
${ }^{1}$ First, the two issues can be distinguished according to the observations taken to need explanation. For the MR (maintenance of recombination), this is the observation that rates of recombination within genomes are variable but considerable in species whose environment is stable, whereas theory would suggest otherwise (see below). On the other hand, Bell (1988: 126) summarised the observations that need to be explained by any hypothesis for the MS (maintenance of sex):

1. the prevalence of sexual reproduction in animals and plants;

2. the taxonomic distribution of asexual taxa as terminal twigs rather than major branches of their phylogenies;

3. other correlates of parthenogenesis, for example, ecological ones with marginal, recent, or disturbed environments (geographic parthenogenesis).

Bell (1982: chapter 5.2.3) contradicted the idea that traits determining recombination rates correlate with traits determining non-selfing sexual reproduction (amphimixis): "The fact that neither of the two major determinants of the amount of recombination, the chiasma frequency and the chromosome number, have the same correlates as amphimixis makes it impossible to sustain the proposition that sex and recombination are merely different aspects of the same phenomenon, to be explained by any single rival hypothesis." (Bell 1982: 435)

Second, the MR and MS differ in their evolutionary costs, and these in turn raise different questions. Recombination incurs a cost because genotypes that have survived and developed to reproduce have thereby proven their adaptedness to the environment they survived in and reproduce in. Natural selection should favour the reduction of recombination rates in a stable environment. This would be possible through favouring mutations at loci affecting recombination rates. Mutations of these modifier genes that reduce recombination rates will increase the probability that adaptive gene combinations stay together. Recombination rates should sink towards zero in stable environments. Hence Turner (1967) asked: "Why does the genotype not congeal?"

Sexual reproduction incurs a different evolutionary cost, the reproductive disadvantage in competition with an asexual mutant that produces as many clonal offspring as sexual females produce daughters plus sons. Facing such a competitor, the selective disadvantage of a sexual female will, all else equal (see footnote 7), be a shipwrecking $50 \%$. Asexual mutants should replace sexual individuals before their recombination rates seriously diminish. Recombination modifiers, on the other hand, do nothing to reduce this demographic cost of sex, whether they decrease crossing-over gradually or stop it abruptly (Felsenstein 1985: 217; 1988: 82). Hence the questions: "What use is sex?" (Maynard Smith 1971b), "Why reproduce sexually?" (Williams and Mitton 1973).

Third, the issues are connected like Siamese twins, because sexual recombination undoes linkage disequilibria and that affects both the MS and the MR. Only a few studies focus on the MR or the MS exclusively (e.g., Krieber and Rose 1986; Edmonds and Rose 1988; Neimann 2004; West-Eberhard 2005; Dagg 2006).
} 
In a letter to C. S. Stock (24 Oct. 1932), Fisher affirmed his hypothesis that sex accelerates the rate of fixation of simultaneously-arising beneficial mutations:

I think you have stated the functions of sex exactly. I imagine forms like the dandelion which are believed to be wholly non-sexual may thrive immensely for a time, but would eventually be so slow in modifying themselves to suit changed conditions that they will not contribute to the ancestry of flora of the remote future. For this purpose, however, a very low percentage of crossing would, I believe, be effective. The penchant for obligate cross-breeding seems to me explainable only by the predominantly unfavourable nature of mutations. (reprinted in Bennett 1983: 264)

Muller (1932) mentioned two advantages of sexual recombination: 1. the continual shifting of genotype frequencies in response to ever-changing environmental conditions, which has been associated with Weismann (Mooney 1995); 2. the simultaneous growth to fixation of permanently favourable mutations, which is similar to Fisher's explanation. He thought the first less important than the second.

There are two ways in which recombination of gene mutations is valuable. One, by far the lesser way, is the providing of an opportunity for continual shifting and readjustment of the relative abundance of different types as external conditions vary back and forth, and here and now one, there and then another combination becomes more advantageous for the maintenance of the species. In this process heterozygosity is an asset, and the disadvantageous combinations continually produced are an insurance against the day when some of them will be needed.

The other, the major value of recombination, is the production, among the many misfits, of some combinations that are of permanent advantage to the species and that eventually become fully established in it as a part of its normal constitution. Without sexual reproduction, the various favourable mutations that occur must simply compete with each other, and either divide the field among themselves or crowd each other out till but the best adapted for the given conditions remains. In asexual organisms, before the descendants can acquire a combination of beneficial mutations, these must first have occurred in succession, within the same lines of descent. In sexual organisms, however, most of the beneficial mutations that occur simultaneously, or in different original lines of descent, can increase largely independently of one another and diffuse through one another, as it were. (Muller 1932: 121)

In both cases the benefit of sexual recombination would be long term and would accrue to the whole population. But this was no explicit group selectionism, because it did not consider this benefit as overcoming the advantage to an individual, asexual mutant.

\section{Sturtevant and Mather in 1938}

Sturtevant and Mather contradicted Muller's assessment of the relative importance of these two advantages by stating that recombination would only be beneficial in stable environments under certain circumstances. It would confer an advantage when it combined two advantageous mutations, but it would be detrimental the next time around. (This implies a focus on individuals rather than populations.) Sturtevant and Mather emphasised the flexible shifting of genotypes in response to ever-changing environments instead:

Two solutions have been proposed, viz.: (a) that recombination makes it possible to obtain favourable combinations of mutant types which have arisen independently, and (b) that recombination increases the "flexibility" of the species in its ability to adapt itself to everchanging environmental conditions.

The former suggestion clearly indicates an advantageous property of recombination, but it would seem that the resulting selection in favor of crossing over would be very small, since such recombination need occur but once. Indeed subsequent recombination would be disadvantageous in breaking up the new favorable combination. [...] 
The second possibility, concerning the "flexibility" of the species, seems to be of greater moment, but it has never been analyzed in sufficient detail to bring out the essential prerequisites for its functioning. (Sturtevant and Mather 1938: 450f)

They suggested that the environment needs to change frequently between conditions favouring different genotypes (Sturtevant and Mather 1938: 451). But they did not assert that the environment would need to change as frequently as sexual reproduction occurred, in order for this advantage to accrue to individuals. Under stable environmental conditions, however, selection should reduce recombination, for example through inversions.

\section{Mather in 1943}

Mather (1943) saw the individual cost of recombination, separating favourable gene combinations, and suggested a trade-off between present fitness and future flexibility:

Heritable variability is necessary for adaptive change, but, in that it implies some individuals departing from the optimum, it lowers present fitness [...] The success of any organism in competition with its contemporaries, must depend on the extent to which it reconciles these needs. Failure to achieve an adequate balance spells either its own doom, on the one hand, or that of its descendants, on the other. Existing organisms must therefore have descended from those which had most adequately balanced the advantages of fitness and flexibility in the past. The organisms of the future will equally be descended from those which, to-day, best reconcile the needs of fitness and flexibility, the rest dying out sooner or later. (Mather 1943: 44)

\section{Fisher in 1945 and 1958: 'The benefit of the species'}

Fisher denied the plausibility of group selection in a letter to J. F. Crow on 23 June 1945. 2 In the second edition of The Genetical Theory of Natural Selection, however, he admitted the possible species-benefit of sexuality:

... Any characters ascribed to interspecific selection should of course characterize, not species, but whole genera or families, and it may be doubted if it would be possible to point to any such character, with the possible exception, as suggested in Chapter VI, of sexuality itself, which could be interpreted as evolved for the specific rather than for the individual advantage. (Fisher [1958: 50]1999: 280)

\section{Muller in 1958}

In the same year Muller attempted to quantify the degree to which sexual recombination accelerates evolution, but he also recognised the individual cost of sex in passing:

It is true that some groups of organisms, including even higher organisms, in every period of the earth's history, have dispensed with sexual reproduction in fact or in effect, and that this has given them the considerable temporary advantage of being able to multiply without having to wait for the nuisance of finding and pairing with one another first. But these can have only a transitory splurge and are doomed to fall behind in the long evolutionary race and to disappear. They furnish an illustration of the short sightedness, the opportunism, of natural selection. The stem forms of evolution, from which the organisms of later periods will be derived, are those that pay their tax to sexuality and are repaid in novel developments. (Muller 1958: 153)

\footnotetext{
2"Thanks for your letter with the interesting discussion of intercommunal selection. [Dr. J. F. Crow had written asking Fisher to comment on a discussion paper on the roles of inter- and intra-population selection.] In thinking about this subject in the past I have been impressed by the relatively long life ascribable to such 'perfectly insulated' communities, and, therefore, with the implausibility of ascribing insulation which shall be perfect relative to their long existence. In fact, I think that complete insulation of the degree required, such as could of course occur through geological changes, must be taken to preclude real competition between the imagined groups." (Quoted in Bennett 1983: 189)
} 


\section{Maynard Smith in 1958}

In 1958, again, John Maynard Smith popularised the established knowledge of evolutionary theory for non-specialists, updated with Drosophila genetics. Already in this work he analysed fully what would later become the paradox of sex:

If the rate of increase of an animal population were limited by the number of eggs which each female could lay, which in turn depended on how much food a female could eat and transform into eggs, then a population consisting entirely of parthenogenetic females would increase twice as fast as would a population of equal numbers of males and females. From the point of view of reproduction, males are a waste of living material. (This argument does not hold for hermaphroditic organisms, or for those animals in which both parents help to feed the young.)

The compensating advantage of the sexual process is that it increases the range of potential variation in a population, and therefore its evolutionary plasticity. (Maynard Smith 1958: 138)

However, this insight neither perplexed Maynard Smith nor threw him into crisis. He simply concluded:

Now if the advantage of sexual reproduction is that it increases the range of potential variation in a population, then the advantage refers to the population as a whole, and not to any particular individual in it. It follows that sexual reproduction has been established as the rule, both in animals and plants, because selection favoured some populations at the expense of others. This forms a contrast to the examples discussed in the last chapter, in which the 'unit' selected was the individual and not the population. (Maynard Smith 1958: 139)

\section{Stebbins at a centennial celebration in 1959}

The University of Chicago organised a celebration of the centennial of Darwin's On the Origin of Species and published the proceedings in three volumes. The third volume reports the deliberations of the participants concerning various issues in evolutionary biology. In particular, one panel chaired by Julian Huxley and Alfred E. Emerson and attended by Daniel I. Axelrod, Theodosius Dobzhansky, E. B. Ford, Ernst Mayr, A. J. Nicholson, Everett G. Olson, C. Ladd Prosser, G. Ledyard Stebbins, and Sewall Wright dealt with the evolution of sex as an illustration of the evolutionary process. Stebbins formulated their consensus as a compromise between future and present needs:

Why is it that in higher organisms sex seems so essential and is never lost, whereas such organisms as fungi and bacteria get along for very long periods without sex or with only a very small amount of genetic recombination? [...] Some years ago, Kenneth Mather pointed out that the genetic recombination system must establish a compromise between two conflicting needs. One need is genetic insurance - generating sexual combinations that at present may have no selective value but may become essential in the future when the environment changes. The other need is to generate the largest possible number of individuals that are fit at the present time. And the balance - the compromise between these needs - is likely to be very different in different organisms.

Take, for instance, a bacterial colony in which millions of individuals are produced in one day, with the generation time a tiny fraction of what it is in man. Here new genotypes can perhaps be generated in large part by occasional mutation or even successions of mutations, as in the adaptation of bacteria to streptomycin. In this case, sex is perhaps of less selective value than in the slowly reproducing higher animals. And in plants the larger, more slowly reproducing perennials and woody plants usually have a high degree of cross-fertilization and genetic recombination through a high chromosome number, whereas the weeds - the pioneers - usually have self-fertilization and sometimes asexual reproduction. This is associated with the fact that a plant in a vacant and relatively uniform habitat is most successful if 
it generates a large number of offspring similar to itself. (Stebbins in Tax \& Callender 1960: 126).

\section{Crow and Kimura in 1965}

Crow and Kimura (1965) are usually credited with explicating the group selection implications of early explanations:

The development of sexual reproduction confers no immediate advantage on the individual in which this occurs. In fact, the result is far more likely to be deleterious. The benefit is only to the descendants, perhaps quite remote, and to the population as a whole. Thus, it seems likely that the selective mechanism by which recombination was established was intergroup selection. [...] On the other hand, despite the great evolutionary advantage of sexual reproduction, there are immediate advantages in return to asexual reproduction. An advantageous type whose recombinant progeny were disadvantageous would have an advantage for its immediate descendants by developing an asexual mode of reproduction, other things being equal. (Crow and Kimura 1965: 448)

This, however, did not entail a paradox or crisis for them either. On the contrary, they concluded:

This all accords with the conventional belief that sexuality developed very early in the evolution of living forms and is therefore found in all major groups; but that numerous independent retrogressions to vegetative reproduction continue to occur, conferring an immediate advantage but a long time evolutionary disadvantage. (Crow and Kimura 1965: 448)

Maynard Smith (1968) also did not question their general conclusion, but criticised a specific assumption they made in order to model Muller's hypothesis that recombination serves to accelerate the fixation of simultaneously occurring beneficial mutations. Maynard Smith (1968) modelled a counter-example of an infinite population with mutants occurring in deterministic frequencies rather than being unique, initially. He concluded that recombination helps in changing environments instead. This exchange caused no feelings of either anomaly or paradox for him.

Later, Felsenstein (1974: 741) emphasised the critical difference between models of finite populations, where favourable mutants are unique individuals, and infinite model populations, where all possible genotypes are present at equilibrium frequencies from the start. That is, the differing outcomes forecast by Crow and Kimura (1965) and by Maynard Smith (1968) were due to the absence or presence of genetic drift. Maynard Smith (1968) missed the advantage of sexual recombination in undoing linkage disequilibria due to drift, because his infinite model population already was in linkage equilibrium. ${ }^{2}$ Felsenstein $(1985 ; 1988)$ unified these and other theories about the advantage of recombination. He distinguished Fisher-Muller theories, in which genetic drift causes linkage disequilibria, from Sturtevant-Mather theories, in which varying selection causes linkage disequilibria. . $^{-}$

\footnotetext{
${ }^{3}$ Felsenstein and Yokoyama (1976) simulated the extreme case of full or zero recombination. The only difference between recombining and non-recombining genotypes was the absence or presence of recombination in the diploid stage. The whole genome consisted of only one pair of homologous chromosomes, in order to exclude recombination through segregating heterologous chromosomes. The model assumptions also resulted in the rate of increase being equal for the recombining and non-recombining parts of the population, and they resulted in the parent-offspring relatedness being equal for all genotypes. (For recombinant offspring $r=0.5$; for non-recombinant offspring $r=(1+0) / 2$. That is, half of the time relatedness was 1 and the other half it was 0 , because in non-recombining types randomly one or the other gamete produced the offspring clonally.)

${ }^{4}$ Recent advances in population genetics have shown that this Hill-Robertson effect can also work in large but finite populations. Recombination breaks down associations between deleterious and beneficial alleles at different loci. The benefit of this effect can, under certain circumstances, even balance the twofold cost of sex (Keightley and Otto 2006; Hartfield and Keightley 2012). That is, within-population selection for recombination could override the advantage of competing but genetically isolated asexual clones.
} 


\section{The parallactic recognition of the paradox}

While Williams started from life-history studies, Maynard Smith's point of departure was population genetics. Though both their approaches were strictly neo-Darwinian, their approaches led them to view the maintenance of sex against different backgrounds. However, neither simply dismissed the other's perspective. Instead, they used their difference in perspective to expose a problem that had previously not been seen, in a way analogous to how our brains use the parallax between our eyes to acquire 3dimensional information. This required mutual respect and trust in each other's observations.

\section{Williams in 1966: life-histories suggest immediate benefit}

Life-history theory explains key events in an organism's life-cycle as shaped by natural selection. In organism with asexual and sexual modes of reproduction, the sexual mode occurs when the offspring meets unpredictable conditions (Bonner 1958). An example is when dispersal stages are produced. Williams came from this tradition and tried to explain the maintenance of sex in terms of life-history theory. $\mathrm{He}$ interpreted sexual reproduction as a life-history adaptation:

The machinery of sexual reproduction in higher animals and plants is unmistakably an evolved adaptation. [...] Reproduction is sexual if it produces offspring with new combinations of the parental genes, and does so by means of machinery designed to produce that result. (Williams [1966]1996: 125)

That is, he took sexual reproduction to be an adaptation and went on to discuss whether it was a group adaptation or an individual adaptation. His terms were 'biotic' and 'organic' for group and individual adaptation respectively.

Williams argued for individual ('organic') adaptation in terms of life-history evolution (Williams [1966] 1996: 130-133). In life-cycles with sexual and asexual phases, sexual reproduction usually occurs when offspring face environmental conditions producing different selective pressures from those faced by their parents. For example, the dispersal stages of many organisms are produced sexually and not clonally. If sexual reproduction were a group ('biotic') adaptation instead, no such pattern should be expected, because the benefit to populations does not depend on the timing of gene-shuffling in life-cycles (Williams [1966] 1996: 131).

\section{Williams on 30 Jan. 1969: letter to Maynard Smith}

Williams informed Maynard Smith that an 'orphaned' paper by Maynard Smith could be included, as the only original contribution, in a collection of published articles on the group selection controversy edited by Williams (1971). He went on:

As long as the paper [Maynard Smith 1971a] continues to point out that there would seem to be an immediate $50 \%$ disadvantage in meiosis, and that explaining sexual reproduction is a major evolutionary problem, it will serve an important function in the book.

Meanwhile I will use the occasion to goad myself into putting together an alternative to the view that the evolutionary significance of sex is in its role in the evolutionary process. It will not really be an alternative to the views expressed in your paper, but rather a supplement to them. Or, more accurately perhaps, it will be a multi-page alternative to your page 16 . I think I can get it to you in about 2 weeks. (Williams, 30 Jan. 1969)

The article eventually published (Maynard Smith 1971a) takes up 10 pages of main text. Hence the manuscript page 16 he referred to (above) would have been towards the end of the article. And indeed, the last section of it deals with the maintenance of sex, the preceding sections being on the connection with the group selection controversy, the classic arguments that sex accelerates the fixation of simultaneous beneficial mutations, the origin of sex, and the sex-ratio.

Hence, Williams's letter to Maynard Smith (see quote above) suggests that they agreed on the diagnosis of the problem but were not completely in accord with respect to their conclusions about it. Maynard 
Smith concluded that the short-term advantage of asexual reproduction was balanced by long-term extinction, and he called this group selection:

It is well known that asexual varieties of plants arise quite commonly, and that their distribution, geographical and taxonomic, suggests that they are successful in the short term but in the long term doomed to extinction. (Maynard Smith 1971a: 171)

\section{Maynard Smith on 13 Feb. 1969: letter to Williams}

Unfortunately, the George C. Williams Collection at Stony Brook holds no correspondence from Williams to Maynard Smith from the two weeks following 30 Jan. 1969 (Lynn Toscano, pers. comm.). In a letter from 13 Feb. 1969, however, Maynard Smith responded to comments by Williams that are not on record in Williams's letter from 30 Jan. 1969. They must be responses to a lost letter. Among other things, he addressed Williams's alternative, that sex is maintained because it produces variable offspring:

I accept that your "rotifers in pitcher plant" model would favour sex. But I am a bit suspicious of models involving a number of generations, in isolation followed by crossing. My "mice in haystacks" model (Nature, 201, 1145) is of this kind, and can produce altruism by group selection.

Everything therefore depends on whether the same mechanisms could operate without cyclical parthenogenesis and a discontinuous environment. I look forward to seeing your arguments on this in more detail.

I did, in fact, consider the advantage of producing genetic variability when writing my article, though I did not work out the idea in any detail. I did not draw what you believe to be the "obvious conclusion" because I found it difficult to devise "model situations", in which sex would win over parthenogenesis because of the variability of the environment. (Maynard Smith, 13 Feb. 1969)

This is interesting for several reasons. It shows that Williams was already groping towards his aphidrotifer model which would later be published in full by Williams and Mitton (1973) and Williams (1975). Secondly, Maynard Smith accepted that this life-history model would favour sex, but maintained that group selection could still play a role in it, as in his haystack model. Thirdly, Maynard Smith clearly saw that his haystack model (see Maynard Smith 1964) could produce altruism through group selection.

\section{Maynard Smith in 1971: population genetics against immediate benefit}

Maynard Smith (1971b) did eventually model situations in which the variability of the environment would favour sexual reproduction, and he concluded that the environment would need to change capriciously for sex to benefit individuals. While Sturtevant and Mather (1938: 450) had already pointed out that crossingover destroys favourable gene combinations as quickly as it creates them, Williams ([1966]1996) seems to have been unaware of that implication. Here, Maynard Smith (1971b) directly addresses Williams:

Two different types of explanation have been offered for the widespread occurrence of sexual processes. The first and most generally accepted explanation is that populations with sex can evolve faster than those without it; hence in the long run sexual populations will survive and asexual ones die out. This, which I will refer to as the "long-term explanation", has not been universally accepted. In particular, G. C. Williams (1966) has criticized it on the grounds that it requires selection to act between groups rather than between individuals. He has therefore preferred what I will call the "immediate explanation", namely that sexually reproducing individuals produce offspring with a wider range of phenotypes, and hence have

\footnotetext{
${ }^{5}$ Conversely, D. S. Wilson claims that Maynard Smith biased the assumptions of his haystack model against group selection and that "Maynard Smith concluded that altruism could not possibly evolve by group selection" (Sober and Wilson 1998: 70). This may be a semantic problem. Maynard Smith took the long term extinction of selfish groups to be group selection, whereas Wilson meant the short-term interaction of trait-groups.
} 
a greater immediate chance of producing some offspring of high fitness. (Maynard Smith 1971b: 319f)

He rejected the idea that offspring variability immediately benefits sexual individuals, because this would require selective pressures to alternate signs between generations; that is, gene combinations that were advantageous in one generation would need to become disadvantageous in the next, and vice versa.

In general, if the correlations between adaptively significant features of the environment commonly change signs between one generation and the next, sexual reproduction will increase the mean fitness of the offspring produced; if, as seems likely to be the more usual situation, such correlations tend to remain the same, sexual reproduction will reduce the mean fitness of offspring. (Maynard Smith 1971 b: 330)

Maynard Smith (1971b: 333) affirmed the orthodox view that sex accelerates the adaptation of populations instead. As before (Maynard Smith 1971a), he mentions the twofold advantage of parthenogenetic mutant females. Such an asexual mutant introduced a new challenge, because its advantage should subvert the benefit of sex to its population. Besides the need to explain the MR, which is to say why recombination rates do not sink to zero within an otherwise sexual species, there was now the additional need to explain the MS, or why asexual species do not crowd out sexual species. 目

Williams (1971: 12) took away the message that "there is near unanimity on the point that sexuality functions to facilitate long-range evolutionary adaptation, and that it is irrelevant and even detrimental to the reproductive interests of an individual." He also perceived the peculiar position of Maynard Smith and his own need for a plausible theory of the MS based on individual selection:

The nearly universal existence of the sexual cycle of meiosis and fertilization $[\ldots]$ is perhaps the most crucial evidence on the importance of group selection. Why this is so is clear from the paper by [Maynard] Smith, who is usually rather firmly on the other side of the controversy. Sexual reproduction must stand as a powerful argument in favor of group selection, unless someone can come up with a plausible theory as to how it could be favored in individual selection. (Williams 1971: 161).

Even Williams's suggestions 'For Further Reading' shed light on the disagreement between Williams and Maynard Smith concerning the immediate benefit of sex. On Maynard Smith (1971b) he suggested:

Here the author [Maynard Smith] elaborates further on some of the ideas expressed in his paper in this volume, and criticizes the theory advanced by the present editor (in entry under Williams, below), that sex can be a favorable reproductive strategy for an individual. (Williams 1971: 205)

About his own book, Adaptation and Natural Selection, he said:

This book develops arguments against group selection in several applications. It also advances reasons for believing that sexual reproduction is advantageous in individual selection, but does not explain how the disadvantage of genetic loss in meiosis [cost of meiosis] can be overcome. (Williams 1971: 205)

\footnotetext{
${ }^{6}$ Graham Bell (1982: 47) aptly described the predicament this caused for evolutionary biologists: "It was the very success of this attack [on group selection] which led population biologists to realize how embarrassing sex is. Most supposedly altruistic behaviours were quickly found either to have concealed advantages for the individual, or else to be directed towards the welfare of closely related individuals. But sex appeared to fit into neither of these categories: if it permits the rapid mobilization of genetic variation, then this may be a matter of vital concern for the population, but does not in itself concern the individual. Evolutionary biologists thus found themselves on the horns of a dilemma: either the apparently unsatisfactory hypothesis of group selection was indeed an adequate explanation for the maintenance of sexuality, or else a quite different hypothesis framed in terms of natural selection must be sought."
} 


\section{Disagreeing about the cost of sex}

All else equal, ${ }^{1}$ an asexual mutant should have twice the rate of increase of sexual individuals. This twofold cost of sex seems to be a common assumption. However, Maynard Smith (1958: 138) had located the cost of sex in the cost of producing males from the very beginning ("From the point of view of reproduction, males are a waste of living material."), whereas Williams ([1966]1996: 130) located the cost of sex in choosing to reproduce by meiosis and gamete fusion rather than by cloning.

Their different understandings of the cost of sex were not due to a conceptual confusion on the part of either of them, but rather to their different commitments. Williams considered asexual and sexual lifehistory strategies to be competing within populations. The competition of isolated taxa was not a matter of selection for him, but of competitive exclusion (Table 1). The cost of meiosis for Williams meant the reduction in transmission of genes to the next generation. This is also called the cost of 'gene sharing,' 'genome dilution' or 'outcrossing' (e.g., Lloyd 1980; Lewis 1987; Lehtonen et al. 2012).

\begin{tabular}{lll}
\hline Difference & Williams & Maynard Smith \\
\hline cost of sex $=$ & cost of meiosis/gamete cooperation & cost of males \\
paradox of sex means & crisis & problem (mute on crisis) \\
MR \& MS & relation not clear & separate issues \\
isolated sexual \& asexual taxa & part of ecology & part of evolutionary biology \\
in the long run, sex & retards adaptation & accelerates adaptation \\
\hline
\end{tabular}

Table 1: Further differences resulting from their parallax in perspectives

The chance a particular allele has of becoming part of a gamete is 1 in asexual reproduction, compared with 0.5 in a fair meiosis. This is irrelevant to an asexual mutant that is reproductively isolated from its sexual competitors, because the competition between isolated taxa depends on their respective rates of increase. For a genetically isolated, asexual clone, transmitting all its genes to all its offspring offers no benefit if its rate of increase does not also exceed that of the competing sexual population.

For example, a hermaphrodite investing half its reproductive resources $(1 / 2 R)$ into haploid eggs and the other half into sperm will not be ousted by a mutant producing asexually developing eggs equivalent to $1 / 2 R$ by virtue of their being diploid. Only a mutant able to convert the $1 / 2 R$ for sperm into additional offspring will have an advantage. If that latter half is also transformed into asexual eggs, the mutant will be genetically isolated from the sexual population, and its advantage will be due to its eliminating the cost of the male function entirely.

If, however, the male function remains operative, $1 / 2 R$ will be invested into asexual eggs and the other $1 / 2 R$ into haploid sperm that can still fertilise the eggs of fully sexual hermaphrodites. That is, the female function of the mutant will be asexual, but the male function will still be sexual. The mutant will not be completely isolated genetically from the sexual population, and the phenomenon of genome dilution will occur.

Charlesworth (1980) considered this case for outbreeding hermaphrodites. As genome dilution affects the mutant's investment in sperm but not in eggs, it will gain a 1.5-fold advantage. The mutant pays the cost of $50 \%$ genome dilution for its sperm $(1 / 2 R \cdot 0.5=1 / 4 R)$ but not for its eggs $(1 / 2 R \cdot 1)$. The sum $(3 / 4 R)$ will be 1.5 times the return on investment for fully sexual outbreeding $(1 / 2 R \cdot 0.5+1 / 2 R \cdot 0.5=1 / 2 R)$. The population consequences are more complex than the individual benefits and depend on whether the mutant sperm transforms fertilised eggs into asexual or sexual phenotypes.

\footnotetext{
7 "All else equal" means that asexual mutants are as fecund and fit as sexual females, that the latter invest half their reproductive resources into sons, and that males contribute nothing but genes to reproduction. Only if this ceteris paribus clause holds will the cost of sex be twofold.

8“The possibility should also be considered that a high level of adaptation in the great majority of individuals [...] is not the most favourable population structure on a long-range evolutionary timescale. Eshel and Feldman (1970) suggested that there may be some benefit in the capacity of sexual reproduction to retard organic evolution [Williams's term for evolution through individual selection]." (Williams 1975: 169) The point, here, was that over-specialisation would lead to extinction, when the special niche vanished.
} 
Nowadays, genome dilution is often said to be irrelevant for species with separate sexes (e.g., Lehtonen et al. 2012; Stelzer 2015). It would be more precise to say that it is irrelevant for asexual mutants that are genetically isolated. As the following case shows, hermaphroditism is only contingently related to genome dilution. In cyclic parthenogenesis, mutant clones can produce mating males when environmental factors trigger the alternation of generations, but keep producing females asexually through parthenogenesis. In this case, the mutant clone is like the mutant hermaphrodite described above, in that its male function is sexual and its female function asexual, but the sexual functions are allocated to different individuals. The sexes are separate, yet genome dilution still applies.

Because Maynard Smith saw the MS as a matter of selection between a sexual population and genetically isolated asexual clones, he needed a concept applicable to this situation. The cost of meiosis, however, only applied to competition between alleles within one population. Maynard Smith (1974: 300; 1978: 3) rejected Williams's (1971: 13; 1975: 9ff.) conception of the cost of meiosis, arguing that it does not occur in isogamous species, because each haploid gamete contributes equal resources to the zygote. Here, a zygote should be twice as large and fertile as an asexual competitor. He instead located the cost of sex in males that contribute nothing but DNA to reproduction. This was in keeping with his first formulation of the problem in Maynard Smith (1958: 138, see quote above).

Williams's conception of the cost of sex as the cost of transmitting only half one's genes to a gamete in meiosis caused misunderstandings with other researchers from the beginning. For example, addressing his earlier self in the third person, Ghiselin (1988: 16) recounted an episode of Williams reviewing one of his submissions:

Williams, who reviewed the paper [Ghiselin (1969)] for the journal in which it appeared, responded by drawing attention to a point that both of them had overlooked, but that had come to his attention from a book by Maynard Smith (1966) [the second edition of Maynard Smith 1958]: that mictic females pass on half as many genes to the next generation as parthenogenetic females do. Ghiselin was not very impressed, suggesting, among other things, that parthenogenetic clones are not part of the sexual population. This of course was the "paradox of meiosis," which suggested that any proper theory of sex would have to give not just a competitive edge, but a twofold competitive edge, to organisms that reproduce sexually.

Unfortunately, the initial letter from Williams to Ghiselin is missing from the George C. Williams Collection (Lynn Toscano, pers. comm.), but Ghiselin's response sheds a light on a common misunderstanding of Williams's conception:

You have assumed that a parthenogenetic form would have twice as many offspring as a sexual one. Actually, as you seem to imply, the sexual organism has just as many offspring, but only transmits half as much of its genome to each. Now, the crucial issue is, would parthenogenesis increase its possessor's contribution to the gene pool of its species? If the parthenogenesis were complete, the answer would certainly be no, for parthenogenesis would of necessity exclude gene flow into the population. (Ghiselin, 21 May 1968)

That is, Ghiselin simply rejected Williams's premise that sexual and asexual life-history strategies compete within one species.

A review by Williams of a submission to the fournal of Theoretical Biology (Treisman and Dawkins 1976), however, shows that Williams understood the difference between the cost of meiosis and that of males very well:

With their making sexual and asexual reproductive modes to define separate populations, they should invoke, not selection theory but competitive exclusion. If the populations need the same resources, I would assume that the competition would be won by the population that does not waste resources on males. (Williams, 13 Nov 1975)

That is, Williams clearly saw the cost of males, but he relegated it to ecology rather than evolution. $\mathrm{He}$ published this distinction in reviewing Maynard Smith's book: 
I think that the primary disadvantage of sexual reproduction in relation to asexual is most fruitfully formulated as a paradox of kin selection - an organism devotes resources to the production and care of a more distant $(r=0.5)$ rather than a close $(r=1)$ relative. This formulation provides a number of advantages. In its focus on genes identical by descent, kin selection is genetically explicit and relates directly to evolution. Maynard Smith's economic argument (resources wasted on males) makes it easy to overlook the fundamental distinction between (1) the evolutionary problem of sexual and asexual reproduction as alternative character states in a population, and (2) the purely ecological question of competition between a clone and a Mendelian population. (Williams 1978: 298)

Williams (1980) affirmed this distinction ${ }^{9}$, and he went on to specify his genetic concept as the sociobiological cost of gamete cooperation (Williams 1980: 372), when kin selection is prevented by outbreeding (see also Williams 1988: 294f; Dagg 2012). He wondered why a cheat-mutation does not spread that excludes the haploid genome of the other gamete, when gametes are unrelated? Egg piracy, now known as androgenesis (McKone and Halpern 2003), was Williams's counter-example. In egg piracy male gametes incur no cost but reap a twofold benefit from cheating eggs. Isogamous species also pay this cost, but it declines with inbreeding. Self-fertilisation will effectively prevent cheats from invading a population.

These different conceptions of the cost of sex agreed with the researchers' different perspectives. Maynard Smith (1978) conceived the MS as a matter of competition between isolated asexual and sexual taxa and separated this issue conceptually from the MR within a population/species. He therefore needed to see asexual mutants as isolated from the sexual population and proposed a concept applying to that situation. Williams, on the other hand, considered asexual and sexual life-history strategies to be competing within one population. The competition of isolated taxa was a matter of ecology to him. He therefore could not switch to the cost of males when his concept lost favour, and suggested the cost of gamete cooperation within out-crossing species instead (Williams 1980; 1988). This kept the issue a matter of selection within species.

Some life-history models of Williams could yield an immediate benefit

Williams and Mitton (1973) stated the established view as follows:

Those who have seriously concerned themselves with the evolutionary significance of sexuality have almost universally rejected any possibility of sexual reproduction being a favorable character in the usual sense of giving an immediate advantage in relation to an alternative character (asexual reproduction). (Williams and Mitton 1973: 545)

They went on to propose an improved theory, based on individual selection, in terms of life-cycle models (Williams and Mitton 1973; Williams 1975).

These started from cyclic parthenogenesis (as in the aphid-rotifer model) and arrived at life-cycles with no asexual mode (as in the elm-oyster model). They either assumed a recurring dispersal of offspring into uncertain environments (aphid-rotifer model) or a saturated environment with fine-grained heterogeneity, in which only those genotypes with the best genetic fit to a rare vacancy survived (elm-oyster model). That is, a clonal offspring would usually fit best a patch already occupied by its own parent and would suffer from sib competition, whereas a sexually-produced offspring might rarely fit best into an opening elsewhere. That is, Williams tried to solve the paradox within his initial life-history perspective.

\section{Proclaiming crisis as a call to arms against group selection}

Williams (1975) proclaimed a crisis in one sentence, but proposed to remedy it by making minimal modifications to his theory.

\footnotetext{
${ }^{9}$ "I believe that understanding has been hampered by failure to distinguish the ecological from the evolutionary problem of sexuality. In important ways, insights gained from conceptual or experimental comparisons of sexual populations and competing clones (the ecological problem) may be misleading in relation to sexual and clonal reproduction as alternative processes in a population (the evolutionary question with which I am concerned here).” (Williams 1980: 372)
} 
This book is written from a conviction that the prevalence of sexual reproduction in higher plants and animals is inconsistent with current evolutionary theory. My purpose is to propose minimal modifications of the theory in order to account for the persistence of so seemingly maladaptive a character. Many well informed readers may disagree with much of my reasoning, but I hope at least to convince them that there is a kind of crisis at hand in evolutionary biology. (Williams 1975: v)

How does identifying a crisis fit with making only minimal modifications? The following statement suggests that the purpose of proclaiming this crisis was a call to arms:

You may not have noticed, but the resulting crisis was heard in laboratories and lecture halls around the world. A new generation of evolutionary biologists heard the battle cry and went on the offensive. (Michod 1995: xvi)

The paradox meant crisis for Williams because he had argued that group selection was practically irrelevant and because he had suggested an alternative explanation for the MS (Williams [1966] 1996: chapter 5) which continued to fail Maynard Smith's scrutiny. Maynard Smith, on the other hand, had allowed an exceptional and limited role for group (species) selection within the MS as early as 1958. Consequently, a containment of group selection within the MS was okay for him, and he never used terms eliciting the spectre of crisis.

\section{Maynard Smith on 23 Feb. 1975: letter to Williams}

Having read Williams's book (1975), Maynard Smith addressed some of its points. He first stated that the life-history perspective (which he called 'the comparative approach') was compatible with his view.

Therefore, let us accept that, if there are sexual and vegetative phases in a life cycle, the sexual one almost always precedes dispersal. This seems compatible with a "species-selection" explanation (? should we distinguish between "group" and "species" selection?). i.e. Those species which abandoned sex are (mostly) extinct. But, within a species, those individuals which use sex only for dispersal are fitter than those which use sex all the time. (I'm not sure this argument makes sense!) (Maynard Smith, 23 Feb. 1975; square brackets in the original were replaced by parentheses)

Williams (1975) claimed that an immediate benefit for sexual reproduction must exist in species, where both modes of reproduction coexist stably within a life-cycle. Otherwise the asexual mode would increase at the expense of the sexual. Maynard Smith thought that this 'balance argument' was not cogent.

This argument is decisively in favour of an immediate advantage for sex - but only in those cases where there is no "dispersive" difference between the two methods. Thus suppose a strawberry can reproduce asexually (by runners) or sexually (by dispersive seeds). Suppose all individuals are genetically identical, except for a set of alleles altering the balance between sexual and asexual methods. Presumably both methods would remain, because of the advantage of dispersion. But if a mutant able to produce dispersive asexual seeds were to arise, it would be established. It follows that your argument, to be decisive, requires evidence that asexual methods of producing all "physiological" types of propagule are possible, and do arise by mutation. Otherwise, I could explain strawberries as you explain vertebrates. [...]

But I don't think you distinguish clearly enough between cases in which we can be sure the balance is between sexual and asexual methods, and those in which it might be between dispersal and local growth. (Maynard Smith, 23 Feb. 1975)

Where Williams (1975) explained the relative lack of asexual vertebrates with evolutionary constraints, Maynard Smith also invoked constraints on producing dispersal stages asexually (see also Maynard Smith 1978: 61f).

Thereafter, he expressed that he was happy with Williams's life-history models, but that one assumption made it difficult to model them more rigorously: 
Unfortunately, if you assume that each $\uparrow$ lays several eggs in each "patch", analytical models become very difficult. I have a Monte Carlo model of this kind running. I am confident it can give a short-term advantage to sex. It is really only an extension of your models. (Maynard Smith, 23 Feb. 1975)

\section{Life histories that do the trick are unlikely to exist in real species}

Maynard Smith published the above-mentioned Monte Carlo model in 1976. He translated the lifehistory models of Williams and Mitton (1973) into stochastic simulations with environmental heterogeneity on a fine-grained scale, and in which sibs competed for patches, but not with their parents. This reflected Williams's assumption that each female lays several eggs in each patch (see quote above).

Maynard Smith (1976: 248ff) found that sexual reproduction would be advantageous through reducing sib-competition only if none of the different selective features of a patch were correlated and none of the different genes under selection were correlated either. Although the model could yield a twofold immediate advantage for sex in theory, these requirements made it seem inapplicable to reality. Maynard Smith (1976: 257) concluded: "One is left with the feeling that some essential feature of the situation is being overlooked."

\section{Conclusion}

Williams and Maynard Smith used their different perspectives in a mutually enlightening way, similar to the way our brains use the parallax of our eyes to gain information about three-dimensional relations. In this way they could recognise and raise a problem that had thitherto not been seen clearly. This required a high degree of mutual respect and trust in each other's observations. This dynamic exemplifies a form of interaction that was both critical and constructive at the same time. It turned neither into an infertile controversy nor into so close a cooperation that it yielded co-authored research articles. (They only ever co-authored a short comment, refuting a letter to the editors of The American Naturalist in one paragraph; see Maynard Smith and Williams 1976.) But their interaction resulted in seminal publications on both sides that raised the maintenance of sex as a major issue for evolutionary biology.

\section{Acknowledgements}

Thanks to Joe Felsenstein for answering questions and letting me see his correspondence with John Maynard Smith, Lynn Toscano, Assistant Head of the Special Collections and University Archives at the Stony Brook University Libraries, Jonathan Pledge, Curator of Politics and Public Life at the British Library, as well as to Julian and Sean Maynard Smith for help on copyright issues with the British Library, and to Christopher Eliot for help with editing.

\section{Literature cited}

Bell, G. 1982. The masterpiece of nature. London: Croom Helm.

Bell, G. 1988. Uniformity and diversity in the evolution of sex. In The evolution of sex: an examination of current ideas. Ed. by RE Michod and BR Levin. Sunderland, MA: Sinauer Associates: 126-138.

Bennett, JH. 1983. Natural selection, heredity, and eugenics: Including selected correspondence of R.A. Fisher with Leonard Darwin and others. Oxford: Clarendon Press.

Bonner, JT. 1958. The relation of spore formation to recombination. The American Naturalist 92: 193-200.

Charlesworth, B. 1980. The cost of sex in relation to mating systems. Fournal of Theoretical Biology 84: 655-671. 
Churchill, FB. 1968. August Weismann and a break from tradition. Fournal of the History of Biology 1: 91-112.

Churchill, FB. 2010. August Weismann embraces the protozoa. Fournal of the History of Biology 43: 767-800.

Crow, JF and M Kimura. 1965. Evolution in sexual and asexual populations. The American Naturalist 99: 439-450.

Dagg, JL. 2006. Could sex be maintained through harmful males? Oikos 112: 232-235.

Dagg,JL. 2012. The paradox of sexual reproduction and the levels of selection. Philosophy \& Theory in Biology 4. Retrieved 10 Sept. 2012. doi: http://dx.doi.org/10.3998/ptb.6959004.0004.001

Edmonds, DE and MR Rose. 1988. Reproductive wastage and the evolution of genetic systems. Fournal of Theoretical Biology 132: 247-250.

Eshel, I and MW Feldman. 1970. On the evolutionary effect of recombination. Theoretical Population Biology 1: 88-100.

Felsenstein, J. 1974. The evolutionary advantage of recombination. Genetics 78: 737-756.

Felsenstein, J. 1985. Recombination and sex: is Maynard Smith necessary? In Evolution. Essays in honour of John Maynard Smith. Ed. by PJ Greenwood, PH Harvey and M Slatkin. Cambridge: Cambridge University Press: 209-220.

Felsenstein, J. 1988. Sex and the evolution of recombination. In The evolution of sex: an examination of current ideas. Ed. by RE Michod and BR Levin. Sunderland, MA: Sinauer Associates: 74-86.

Felsenstein, J and S Yokoyama. 1976. The evolutionary advantage of recombination. II. Individual selection for recombination. Genetics 83: 845-859.

Fisher, RA. [1930; 1958] 1999. The genetical theory of natural selection, a complete variorum edition. Ed. by Henry Bennett. Oxford: Oxford Univ. Press.

Ghiselin, MT. 21 May 1968. Letter to George C. Williams. Box 1, George C. Williams Collection, Special Collections, Stony Brook University Libraries.

Ghiselin, MT. 1969. The evolution of hermaphroditism among animals. Quarterly Review of Biology 44: 189-208.

Ghiselin, MT. 1988. The evolution of sex: a history of competing points of view. In The evolution of sex: an examination of current ideas. Ed. by RE Michod and BR Levin. Sunderland, MA: Sinauer Associates: $7-23$.

Hartfield M and PD Keightley. 2012. Current hypotheses for the evolution of sex and recombination. Integrative Zoology 7: 192-209.

Keightley, PD and SP Otto. 2006. Interference among deleterious mutations favours sex and recombination in finite populations. Nature 443: 89-92.

Krieber, M and MR Rose. 1986. Males, parthenogenesis, and the maintenance of anisogamous sex. Fournal of Theoretical Biology 122: 421-440.

Lehtonen, J, MD Jennions and H Kokko. 2012. The many costs of sex. Trends in Ecology \& Evolution 27: $172-178$.

Lewis, WMJr. 1987. The cost of sex. In The evolution of sex and its consequences. Ed. by SG Stearns. Basel: Birkhäuser Verlag: 33-57.

Lloyd, DG. 1980. Benefits and handicaps of sexual reproduction. Evolutionary Biology 13: 69-111.

Lustig AJ. 2000. Sex, death, and evolution in proto- and metazoa, 1876-1913. Fournal of the History of 
Biology 33: 221-246.

Mather, K. 1943. Polygenic inheritance and natural selection. Biological Revieres 18: 32-64.

Maynard Smith, J. 1958. The Theory of Evolution. Hammondsworth, Middlesex: Penguin Books.

Maynard Smith, J. 1964. Group selection and kin selection. Nature 201: 1145-7.

Maynard Smith, J. 1968. Evolution in sexual and asexual populations. The American Naturalist 102: 469-473.

Maynard Smith, J. 13 Feb. 1969. Letter to George C. Williams. Box 1, George C. Williams Collection, Special Collections, Stony Brook University Libraries.

Maynard Smith, J. 1971 a. The origin and maintenance of sex. In Group selection. Ed. by GC Williams. New Brunswick, NJ: Aldine Transaction, 163-175.

Maynard Smith, J. 1971 b. What use is sex? Fournal of Theoretical Biology 30: 319-335.

Maynard Smith, J. 1974. Recombination and the rate of evolution. Genetics 78: 299-304.

Maynard Smith, J. 23 Feb. 1975. Letter to George Williams. Add MS 86612, Notes on sex, Subject files, John Maynard Smith Archive, Western Manuscripts Collection, British Library, London.

Maynard Smith, J. 1976. A short-term advantage for sex and recombination through sib-competition. Fournal of Theoretical Biology 63: 245-258.

Maynard Smith, J. 1978. The evolution of sex. Cambridge: Cambridge Univ. Press.

Maynard Smith, J. and GC Williams. 1976. Reply to Barash. The American Naturalist 110: 897.

McKone, MJ and SL Halpern. 2003. The evolution of androgenesis. The American Naturalist 161: $641-656$.

Meirmans, S. 2009. The evolution of the problem of sex. In Lost Sex. Ed. by I Schön, K Martens and P van Dijk. Heidelberg: Springer Science: 21-46.

Meirmans, S and R Strand. 2010. Why are there so many theories for sex, and what do we do with them? Fournal of Heredity 101: S3-S12.

Michod, RE. 1995. Eros and Evolution. Reading, MA: Addison-Wesley.

Mooney, SM 1993. The evolution of sex - variation and rejuvenescence in the $19^{\text {th }}$ century and today. BioScience 43: 110-113.

Mooney, SM. 1995. H. J. Muller and R. A. Fisher on the evolutionary significance of sex. Fournal of the History of Biology 28: 133-149.

Muller, HJ. 1932. Some genetic aspects of sex. The American Naturalist 66: 118-138.

Muller, HJ. 1958. Evolution by mutation. Bulletin of the American Mathematical Society 64: 137-160.

Neiman, M. 2004. Physiological dependence on copulation in parthenogenetic females can reduce the cost of sex. Animal Behaviour 67: 811-822.

Stelzer, C-P. 2015. Does the avoidance of sexual costs increase fitness in asexual invaders? Proceedings of the National Academy of Sciences 112: 8851-8858.

Sturtevant, AH and K Mather. 1938. The interrelations of inversion, heterosis and recombination. The American Naturalist 72: 447-452.

Tax, S and G Callender, Eds. 1960. Evolution after Darwin, vol. 3. Issues in evolution. Chicago: University of Chicago Press.

Treisman, M and R Dawkins. 1976. The "Cost of Meiosis": is there any? Fournal of Theoretical Biology 63: 479-484. 
Turner, JRG. 1967. Why does the genotype not congeal? Evolution 21: 645-656.

West-Eberhard, MJ. 2005. The maintenance of sex as a developmental trap due to sexual selection. Quarterly Review of Biology 80: 47-53.

Williams, George C. ([1966]1996). Adaptation and natural selection. Princeton: Princeton University Press.

Williams, GC. 30 Jan. 1969. Letter to John Maynard Smith. Box 1, George C. Williams Collection, Special Collections, Stony Brook University Libraries.

Williams, GC. 1971. Group selection. New Brunswick, NJ: Transaction Publishers.

Williams, GC. 1975. Sex and evolution. Princeton: Princeton University Press.

Williams, GG. 13 Nov. 1975. Letter to John Maynard Smith including "A reaction to Treisman and Dawkins." Box 2, George C. Williams Collection, Special Collections, Stony Brook University Libraries.

Williams, GC. 1978. A review of The Evolution of Sex by John Maynard Smith. Quarterly Review of Biology 53: 287-289.

Williams, GC. 1980. Kin selection and the paradox of sexuality. In Sociobiology: Beyond nature/nurture? Ed. by GW Barlow and J Silverberg. Boulder, GO: Westview: 371-384.

Williams, GC. 1988. Retrospect on sex and kindred topics. In The evolution of sex: an examination of current ideas. ed. RE Michod and BR Levin. Sunderland, MA: Sinauer Associates: 287-298.

Williams, GC and JB Mitton. 1973. Why reproduce sexually? Fournal of Theoretical Biology 39: 545-554.

Winther, RG. 2001. August Weismann on germ-plasm variation. Fournal of the History of Biology 34: $517-555$.

Copyright (C) 2016 Author(s).

This is an open-access article distributed under the terms of the Creative Commons

Attribution-NonCommercial-NoDerivs license, which permits anyone to download, copy, distribute, or display the full text without asking for permission, provided that the creator(s) are given full credit, no derivative works are created, and the work is not used for commercial purposes.

ISSN 1949-0739 